\title{
Cold Agglutinin
}

National Cancer Institute

\section{Source}

National Cancer Institute. Cold Agg/utinin. NCI Thesaurus. Code C62221.

An autoantibody against a red blood cell surface antigen that causes the cells to clump when the blood is cooled below the normal body temperature (the clumping is most pronounced at temperatures below 78 degrees). Presence of cold agg lutinins may be indicative of mycoplasmal pneumonia, mononucleosis, mumps, measles, scarlet fever, some parasitic infections, cirrhosis of the liver, and some types of hemolytic anemia. 